\title{
DETERMINAN PEMANFAATAN FASILITAS KESEHATAN SEBAGAI TEMPAT PERSALINAN DI KOTA PALANGKA RAYA
}

\author{
Determinat of Utilization Health Facilities for Place of Childbirth in Palangka Raya \\ Erina Eka Hatini \\ Politeknik Kesehatan Kemenkes Palangka Raya \\ ( erinaekahatini@gmail.com )
}

\begin{abstract}
ABSTRAK
Data SDKI tahun 2012 menunjukkan bahwa Propinsi Kalimantan Tengah menduduki peringkat terendah ke-3 yaitu hanya sekitar 32\% Persalinan di Faskes setelah Propinsi Maluku dan Propinsi Sumbar (BPS and Macro International, 2013). Data Pusdatin Kemenkes RI, 2017 menunjukkan bahwa Persalinan ditolong tenaga kesehatan di Fasilitas Kesehatan untuk Provinsi Kalimantan Tengah tahun 2016 sekitar 42, 08 \%. Dengan diketahuinya Determinan Pemanfaatan Fasilitas Kesehatan Sebagai Tempat Persalinan Di Kota Palangka Raya diharapkan dapat meningkatkan pemanfaatan Fasilitas Kesehatan Sebagai Tempat Persalinan.

Tujuan Penelitian yaitu mengetahui Determinan Pemanfaatan Fasilitas Kesehatan Sebagai Tempat Persalinan Di Kota Palangka Raya. Rancangan penelitian cross sectional jumlah sampel 164 ibu yang mempunyai bayi usia 0-12 bulan. Variabel bebas adalah determinan pemanfaatan fasilitas kesehatan dan variabel terikat adalah tempat persalinan. Analisis data yang digunakan analisis uni variabel menggunakan distribusi frekuensi dan persentase, analisis bi variabel menggunakan uji chi-square, serta multi variabel menggunakan regresi logistik. Variabel umur, status ekonomi dan riwayat ANC menunjukkan nilai yang bermakna sebagai determinan pemanfaatan Fasilitas kesehatan sebagai tempat persalinan . Variabel pendidikan, pekerjaan, jarak, transportasi pada analisis bivariabel dan multi variabel menunjukkan hubungan yang tidak bermakna sebagai determinan pemanfaatan Fasilitas kesehatan sebagai tempat persalinan. Kesimpulan didapatkan Penelitian menunjukkan hubungan yang bermakna antara umur, status ekonomi dan Riwayat ANC dapat memberika kontribusi sebesar 10\% terhadap pemanfaatan fasilitas kesehatan non pemerintah dengan sebagai tempat persalinan.
\end{abstract}

KataKunci: Determinan,Pemanfaatan Fasilitas Kesehatan, Tempat Persalinan.

\section{ABSTRACT}

Survey Demographics of helath in Indonesia in 2012 show Province of Central Kalimantan contribution the third of lowest rank about 32\% utilization health facilities for deliveries after Province of Maluku an Sumbar. (BPS and Macro International, 2013). Pusdatin Kemnkes RI, 2017 shown deliveries with health provider in Province of Kalimantan Tengah in 2016 about 42,08\%. This research to know determinant of utilization health facilities can increase utilization health facilities for place of child birth in Palangka Raya. This research was a imed to known Determinat of utilization health facilities for place of child birth in Palangka Raya. This research was that used cross sectional study design. The design was a sample size of 164 mothers who had a baby aged 0-12month. The independent variable was determinant of utility health facilities, the dependent variable was Health Facilities for place of child birth. Data analysis used uni variable analysis with frequency and percent age distribution, bivariable analysis with chi-square test, and multivariable analysis with logistic regression. Age of maternal, status of economic and ANC histories variable showed a significant relationship as Determinat of utilization health 
facilities for place of childbirth. Maternal education, mothers occupation, distance beetwen home to health facilities, media of transport showed not significant relationship as Determinant of utilization health facilities for place of child birth. The multi variable result showed a significant relationship between age of maternal, status of economic and ANC histories that could contribute as much as $10 \%$ on Determinat of utilization non government health facilities for deliveries in.

Keywords:Determinant, Utilization of health facilities, Place of childbirth

\section{PENDAHULUAN}

Pemanfaatan fasilitas kesehatan sebagai tempat pertolongan persalinan merupakan salah satu faktor penting untuk mengurangi angka kematian ibu, namun banyak ibu di negara berpenghasilan rendah dan menengah, melahirkan diluar fasilitas kesehatan tanpa bantuan tenaga kesehatan(Gabrysch and Campbell, 2009).

Dampak dari hal tersebut menyebabkan ibu hamil tidak dapat memanfaatkan fasilitas kesehatan sebagai tempat persalinan berisiko untuk tidak memperoleh pelayanan obstetri dan neonatal yang memadai.

Hasil SDKI 2012, Angka Kematian Ibu 359 per 100.000 kelahiran hidup (angka nasional) sedangkan target MDGs 2015 adalah 102 per 100.000 kelahiran hidup. Masih tingginya Angka Kematian Ibu di Kalimantan Tengah terkait akses terhadap pelayanan kesehatan, perilaku pencarian pertolongan (masih banyak persalinan ditolong bukan oleh tenaga kesehatan) serta distribusi fasilitas dan tenaga kesehatan belum merata. Salah satu faktor utama berkontribusi tingginya kematian ibu adalah terbatasnya tempat persalinan yang memadai. Data SDKI 2012 menunjukkan hanya sekitar 63\% persalinan di Fasilitas Kesehatan. (BPS and Macro 2013)

Data SDKI tahun 2012 menunjukkan bahwa Propinsi Kalimantan Tengah menduduki peringkat terendah ke-3 yaitu hanya sekitar $32 \%$ Persalinan di Faskes setelah Propinsi Maluku dan Propinsi Sumbar (BPS and Macro International, 2013). Data Riskesdas, 2013 menyebutkan rendahnya Rumah Tangga di Kalimantan Tengah yaitu kurang dari $40 \%$ mengetahui keberadaan bidan atau rumah bersalin. Data Pusdatin Kemenkes RI, 2017 menunjukkan bahwa Persalinan ditolong tenaga kesehatan di Fasilitas Kesehatan untuk Provinsi Kalimantan Tengah tahun 2016 sekitar 42, $08 \%$.

Berdasarkan data di atas, diketahui bahwa pemanfaatan fasilitas kesehatan masih rendah. Berdasarkan hal tersebut peneliti ingin melihat bagaimana Determinan Pemanfaatan Fasilitas Kesehatan Sebagai Tempat Persalinan Di Kota Palangka Raya? 


\section{METODE PENELITIAN}

Penelitian ini merupakan penelitian observasional dengan rancangan cross sectional dengan besar sampel yaitu 164 ibu yang memiliki Bayi. Pada penelitian ini, penentuan kelompok sampel ditentukan secara purposive sampling .

Penelitian dilakukan di Wilayah Kerja Puskesmas Kereng Bangkirai. Pengumpulan data pada penelitian ini menggunakan data primer yang diperoleh dari pengisian kuesioner oleh peneliti dengan melakukan wawancara pada subjek penelitian.

Analisis data yang digunakan meliputi analisis karakteristik Subjek Penelitian menggunakan distribusi frekuensi dan persentase, Analisis bivariabel yaitu melihat hubungan antara variabel bebas umur, pendidikan, pekerjaan, status ekonomi, jarak, tramsportasi, riwayat ANC dengan variabel terikat Fasilitas kesehatan sebagai tempat persalinan menggunakan uji chi-square, serta Analisis multivariat dilakukan untuk melihat hubungan antara variabel bebas (Faskes tempat persalinan). Analisis yang digunakan untuk mengetahui hubungan tersebut adalah binomial regression (binreg) . Kriteria penilaian yang dipakai adalah dengan memperhitungkan nilai Ods Ratio(OR).

\section{HASIL}

Hasil penelitian menunjukkan deskripsi data karakteristik lbu yang mempunyai
Bayi di Wilayah Kerja Puskesmas Kereng dan Puskesmas Pahandut adalah bahwa sekitar 64,0\% Persalinan di Fasilitas Kesehatan Non Pemerintah dan 36,0\% Persalinan di Fasilitas Kesehatan Pemerintah. Dari variabel umur menunjukkan sebesar 59,1\% responden berusia 20 sampai 35 tahun. Mayoritas Pendidikan responden sekitar 67,7\% adalah Pendidikan Dasar, sekitar $75 \%$ responden tidak bekerja. Karakteristik Status ekonomi menunjukkan 59,2\% pendapatan > Rp. 2.129.431, Jarak ke Fasilitas Kesehatan terdekat sekitar 50\% $\geq$ $3 \mathrm{Km}$ dan $50 \%<3 \mathrm{Km}$. Responden sekitar 93,9 \% memiliki alat transportasi serta 80,5 $\%$ Riwayat Pemeriksaan ANC teratur.

Analisis bivariabel dilakukan untuk mengidentifikasi hubungan antara variabel bebas dan terikat, variabel luar dengan variabel terikat, serta variabel luar dengan variabel bebas. Variabel terikat dalam penelitian ini adalah Persalinan di Fasilitas Kesehatan, variabel bebas adalah Umur, Pendidikan, Pekerjaan, Status Ekonomi, Jarak, Transportasi, Riwayat ANC, Uji statistik yang digunakan adalah chi-square $\left(\mathrm{X}^{2}\right)$ pada tingkat kemaknaan $p$ $<0.05$, untuk melihat determinan pemanfaatan fasilitas kesehatan sebagai tempat persalinan dengan mengetahui nilai Odd Ratio (OR) dengan Confidence Interval (Cl) 95\%.

Hasil analisis menunjukan bahwa variabel umur bermakna secara statistik maupun praktis sebagai determinan 
pemanfaatan fasilitas kesehatan Non Pemerintah sebagai tempat persalinan, hasil analisis menunjukkan bahwalbu dengan umur < 19 tahun mempunyai peluang 2,78 kali lebih tinggi dibandingkan dengan lbu yang yang umur 20 - 35 tahun, sedangkan ibu yang umur > 35 tahun mempunyai peluang 2,38 kali lebih tinggi dibandingkan dengan Ibu yang yang umur 20 - 35 tahun dalam memanfaatkan fasilitas kesehatan Non Pemerintah sebagai tempat persalinan. Variabel status ekonomi juga menunjukkan bermakna secara statistik pada lbu yang dengan status ekonomi pendapatan keluarga $<R p$. 2.129.431 memanfaatkan fasilitas kesehatan Non Pemerintah sekitar 1,99 kali lebih tinggi dibanding keluarga yang status ekonomi pendapatan keluarga $>\mathrm{Rp}$. 2.129.431. Hasil analisis bivariabel juga menunjukkan bahwa lbu yang riwayat ANC tidak teratur memiliki peluang 2,90 kali lebih tinggi memanfaatkan fasilitas kesehatan Non Pemerintah dibanding ibu yang memiliki riwayat ANC teratur.

Hasil analisis bivariabel menunjukkan nilai yang tidak bermakna pada variabel Pendidikan, Pekerjaan, Jarak, Alat transportasi, dimana masing-masing $\mathrm{p}>$ 0,05 dan $95 \% \mathrm{Cl}$ nilainya mencangkup angka satu.

Hasil analisis multivariat menunjukkan adanya hubungan yang bermakna antara umur dengan Fasilitas Kesehatan (OR= 2.45; $95 \% \mathrm{Cl}=1.02-5.88)$, sehingga dapat diasumsikan bahwa ibu yang berusia >
35 tahun mempunyai peluang 2.45 kali memilih Fasilitas Kesehatan Non Pemerintah sebagai tempat persalinan dibanding ibu berusia 20-35 tahun. Demikian juga ibu yang berusia $<20$ tahun diasumsikan mempunyai peluang 4.23 kali memilih Fasilitas Kesehatan Non Pemerintah sebagai tempat persalinan dibanding ibu berusia 20-35 tahun. Hasil analisis juga menunjukkan adanya hubungan yang bermakna antara status ekonomi dengan Pemilihan Faskes sebagai tempat persalinan (OR=2.66; 95\% $\mathrm{Cl}=1.27-5.58)$, sehingga dapat diasumsikan bahwa ibu yang dengan status ekonomi < Rp. 2.129.431 akan mempunyai peluang 2.66 kali lebih besar untuk memilih fasilitas kesehatan non Pemerintah dibanding dengan yang status ekonomi > Rp. 2.129.431.

Variabel Riwayat ANC juga menunjukkan adanya hubungan yang bermakna antara Riwayat ANC dengan Pemilihan Faskes Non Pemerintah sebagai tempat persalinan $(O R=4.11$; 95\% $\mathrm{Cl}=1.46-11.51)$, sehingga dapat diasumsikan bahwa ibu yang riwayat ANC tidak teratur akan mempunyai peluang 4.11 kali lebih besar untuk memilih Fasilitas kesehatan non pemerintah dibanding dengan ibu yang riwayat ANC teratur.

\section{PEMBAHASAN}

Hasil univariat menunjukkan bahwa sebagian responden berada pada usia 
reproduksi sehat. Senewe (2004) mengemukakan bahwa ibu yang berusia 20-34 tahun mempunyai risiko untuk mendapatkan komplikasi pada waktu persalinan 1,3 kali lebih kecil dibanding dengan ibu-ibu yang melahirkan pada usia $<20$ dan $\geq 35$ tahun .

Hasil penelitian menunjukkan sebagian besar responden memiliki pendidikan tingkat dasar. Pokhrel \& Sauerborn (2004) mengemukakan bahwa latar belakang pendidikan ibu mempunyai hubungan yang signifikan dengan pengambilan keputusan pencarian pelayanan kesehatan. Prawira (2000) mengatakan bahwa ibu yang berpendidikan rendah 1,5 kali lebih besar untuk memilih dukun sebagai penolong persalinan dibandingkan dengan ibu yang berpendidikan tinggi. Pendidikan ibu terkait dengan semua jenis perilaku kesehatan (Bellet al., 2003). Pendidikan kesehatan tersebut meliputi manfaat pencegahan, perawatan kesehatan dan kesadaran pentingnya pelayanan kesehatan, menerima informasi baru terkait kesehatan, sosialisasi untuk berinteraksi dengan pelayanan formal di luar lingkungan rumah, familiarity dengan budaya medis modern, akses ke sumber daya keuangan dan asuransi kesehatan.

Status pekerjaan ibu(bekerja atau tidak bekerja) tidak berpengaruh dalam penentuan penolong persalinan, hal ini berhubungan dengan kebiasaan melahirkan sebelumnya. Kebiasaan keluarga dan pengalaman persalinan yang lalu selalu menjadi pertimbangan dan alasan pemilihan penolong persalinan. Pekerjaan terutama wanita, dikaitkan dengan daya beli masyarakat dan tingkat kemandirian wanita yang sangat berpengaruh terhadap kesehatannya. Wanita yang bekerjadan mandiri akan mudah bagi dirinya mewujudkan keinginan untuk memeriksakan kesehatannya kepada petugas kesehatan terutama saat hamil dan bersalin.

Status Ekonomi adalah kemampuan keluarga untukmenghidupi seluruh anggota keluarga yang diukur dengan pengeluaran rata-rata keluarga dalam satu bulan (sesuai standar). Keadaan ekonomi keluarga sangat berperan dalam pengambilan keputusan bertindak mencari pelayanan kesehatan. Keluarga dengan status ekonomi tinggi, umumnya lebih memperhatikan masalah kesehatan, kehamilan dan persalinan, sehingga selalu berupaya mencari pertolongan ke pelayanan kesehatan apabila mereka sakit atau ada keluhan. Sebaliknya pada keluarga dengan status ekonomi rendah, cenderung lebih memilih dukun sebagai penolong persalinan (Prawira, 2000).

Keadaan ekonomi keluarga berkaitan dengan pengambilan keputusan dalam pencarian dan pemanfaatan pelayanan kesehatan. Pada keluarga dengan status ekonomi rendah, keinginan untuk mendapatkan pelayanan kesehatan yang profesional menjadi bukan prioritas utama. Keluarga lebih memikirkan cara untuk memenuhi kebutuhan hidup sehari- hari. 
Pokhrel \& Sauerborn (2004).

Variabel pendidikan, pekerjaan, jarak, transportasi pada analisis multivariat menunjukkan hubungan yang tidak bermakna dengan pemanfaatan fasilitas kesehatan sebagai tempat persalinan. Hal ini kemungkinan disebabkan sampel yang homogen.

\section{KESIMPULAN}

Berdasarkan hasil analisis penelitian dapat disimpulkan bahwa Variabel umur, status ekonomi dan riwayat ANC menunjukkan nilai yang bermakna sebagai determinan pemanfaatan Fasilitas kesehatan sebagai tempat persalinan. Sehubungan dengan hasil penelitian maka disarankan agar bagi tenaga kesehatan untuk lebih mempromosikan pemanfaatan Fasilitas Kesehatan Pemerintah sebagai tempat persalinan untuk ibu-ibu hamil terutama bagi yang berusia $<20$ atau $>35$ tahun, selain itu juga mempromosikan bahwa Fasililtas Kesehatan Pemerintah biayanya lebih rendah dibanding dengan Faskes non pemerintah, selain itu meningkatkan kualitas pelayanan ANC bagi ibu hamil serta Fasilitas Kesehatan Pemerintah untuk lebih meningkatkan kualitas dan kuantitas sarana prasarana dan SDM yang berkualitas agar dapat menjamin mutu pelayanan bagi masyarakat.

\section{DAFTAR PUSTAKA}

Balitbangkes Kemenkes RI (2013) Riset Kesehatan Dasar 2013, Jakarta.

Bell,J.,Curtis,S.L.\& Alayón,S. (2003) Trends in delivery care in six countries DHS Analytical Studies.

BPS \&Macro International (2013) Survei Demografi dan Kesehatan Indonesia 2012, Calverton, Maryland, USA: Macro International.

Gabrysch, S. \& Campbell, O.M.(2009) Still too farto walk: Literature review of the determinants of delivery service use. BMC Pregnancy and Childbirth,9(34):1-18.

Pokhrel, S. \& Sauerborn, R. (2004) Household decision-making on child health care in developing countries: The Case of Nepal. Helath Policy Plan., 19(4): 218-233

Prawira, A. (2000) Determinan penolong persalinan di rumah di Kabupaten Purworejo Jawa Tengah. Yogyakarta: Universitas Gadjah Mada

Pusdatin Kemenkes RI (2017) Data dan Informasi Profil Kesehatan Indonesia. Jakarta.

Senewe, F.P. \& Sulistiyowati, N. (2004) Faktor-faktor yang berhubungan dengan komplikasi persalinan tiga tahun terakhir di Indonesia. (Analisis LAnjut SKRTSurkesnas 2001). Buletin Penelitian Kesehatan. 32 (2): $18-91$ 